\title{
1.
}

\section{British Digital Game Studies}

\author{
Garry Crawford, Esther MacCallum-Stewart, \& Paolo Ruffino
}

\section{Transactions of the Digital Games Research Association}

April 2018, Vol 3 No 3, pp 1-11

ISSN 2328-9422

(C) The text of this work is licensed under a Creative Commons Attribution -- NonCommercial --NonDerivative 2.5 License (http://creativecommons.org/licenses/by-nc-nd/2.5/).

IMAGES: All images appearing in this work are property of the respective copyright owners, and are not released into the Creative Commons. The respective owners reserve all rights.

\section{ABSTRACT}

This paper provides a short and potted recent history of digital games research in Great Britain. We begin this story in 2001. Though a substantial amount of research and writing on digital games has been taking place in Britain since at least the 1980s, for us the turn of the new millennium marks a logical starting point of our recent history. Not only was this the year that Aarseth (2001) marked as 'year one' for 'computer game research', it was also the year that the first major international conference on digital games took place in the UK (in Bristol), and the first time a major British government grant was awarded to undertake 


\section{ToDiGRA}

research on digital gaming. The paper then charts the significant role Britain played in hosting major early international gatherings of (now leading) games researchers, such as those in Bristol and also Manchester. As well as the important crop of early British-authored (text) books that helped shape the direction of this new and emerging discipline. What we then see is a significant growth in British digital games studies focused on a number of key events, research clusters, and publications, and the development of a particular framing of digital games within a wider social, cultural and political context. It is this, we would suggest, that has given British digital game studies its particular flavour and also its important global role in pushing forward research, theory, and key debates.

\section{KEYWORDS}

British, Digital Games, DiGRA, Game Studies, History.

\section{BRITISH DIGITAL GAME STUDIES}

We begin this story in 2001. As with all stories, there is a great deal that happened before our story begins. Many British academics and academics working in Britain (which is not always the same thing) were thinking about, and in some cases researching and writing about, video games long before 2001. Certainly, Surman (2007 p.279) argues that 'some of the earliest, and at the time, most comprehensive work on video games emerged from the humanities departments of British universities in the mid-to-late 1980s. But 2001 seems a good place for us to start, for several reasons. First, this was the year that Espen Aarseth now famously declared as ‘year-one' of 'computer game studies', hence, it seems fitting to outline where British digital game scholarship was at, and how this developed from this starting point drawn by Aarseth. Second, 2001 was the year David Buckingham of the London University Institute of Education won the first major grant from a UK research council to research digital games. Buckingham subsequently appointed Diane Carr 
to head up this project, and soon after they were joined by Andrew Burn. This team were at the forefront of combining different approaches, theories and methodologies, such as drawing on social and educational psychology, and film and literary theory, which allowed them to advance understanding of both the structural and mediated culture of digital games (Surman 2007); and it was this collaboration that would lead to the publication of numerous key texts including the important book by Carr et al (2006) Computer Games: Text, Narrative and Play. Third, this was also the year of the first significant gathering of digital game studies scholars on British soil, at the Game Cultures Conference at the Watershed in Bristol, organised by Helen Kennedy and Jonathan Dovey from the University of the West of England (UWE) (The Play Research Group, online). Papers from this important conference were later published in a special edition of the journal, Game Studies in 2002, edited by Jonathan Dovey, and delegates at this event included both local and international scholars such as Espen Aarseth, Frans Mäyrä, Henry Jenkins, Jesper Juul, James Newman, Celia Pearce and TL Taylor. In particular, Jonathan Dovey recalls this conference as the first time there was a head-to-head discussion on British soil between leading proponents of both the ludology and narratology approaches to games research; an ongoing debate that would shape the direction and nature of game studies for many years to come.

The Bristol Game Cultures Conference would lead to a number of other symposiums organised by the Play Research Group at UWE, including Power Up in 2003, Playful Subjects in 2005, and PSii on Games and Technology in 2006 and 2007. Also, most notably, this 2001 conference laid the foundations of what would lead to the publication of Helen Kennedy and Jonathan Dovey's important book, Game Cultures: Computer Games as New Media in 2006. However, before all of this, the second series of major conferences in the UK, organised by Jason Rutter, were to take place in the North of England, initially Manchester. The first of these conferences was the Playing with The Future: Development and Directions in Computer Gaming held in Manchester in April 2002. This conference attracted what was probably, at that point, the biggest and 
most significant gathering of leading academics in this newly developing field, which included (amongst others) Chris Bateman, Mia Consalvo, Diane Carr, Marinka Copier, Garry Crawford, Simon Egenfeldt-Nielsen, Jesper Juul, Aphra Kerr, Julian Kücklich, and Tanya Krzywinska, plus several representatives from the games industry such as Jason Della Rocca and Michael Rawlinson. This conference was also significant as it was here that informal discussions of the forming of an international association for digital games research began.

As with the Bristol conference, the Manchester meeting was the start of a series of conferences, when Jason Rutter in partnership with a number of local hosts used research council funding to hold a series of game focused symposiums around the UK over the following two years. Also, as with the Bristol conference, the Manchester event led to the publication of a key text in digital games studies; Jason Rutter and Jo Bryce's 2006 edited collection, Understanding Digital Games. This book, as with the conference before it, gathered together some of the leading names in British and international digital games studies, and, along with Carr et al. and Kennedy and Dovey's books of the same year, provided important foundational textbooks for the emerging study of digital games. Over a decade later, these books are still in common use in many undergraduate courses the world over. Similarly, other important books published by British scholars around this time include, amongst others, Barry Atkins' (2003) More than a Game, James Newman's (2004) Videogames, Tanya Krzywinska and Geoff King's two books, Screenplay: cinema/videogames/interfaces (2002) and Tomb Raiders and Space Invaders: videogame forms and contexts (2006), and Valerie Walkerdine's (2007) Children, Gender, Video Games; books that have left a lasting impression on the shape of contemporary digital games studies and helped solidify the position of British academics as being at the forefront of defining key directions in this emerging discipline.

In his analysis of key texts from British scholars in this period, Marcus Leaning (2012) notes that the topics being discussed in these volumes 
included, unsurprisingly for the time, aspects of ludology and narratology, but also evident is a considerable focus on players, gamer culture, the game industry, and representation. Hence, as well as contributing to the existing key debates of the time, British digital game studies (if such a thing exists) was notably also pushing forward debate into the areas of social, cultural and political aspects of gaming. As Surman (2007 p.279) wrote of Dovey and Kennedy’s 2006 book 'eschewing the polemical and purist approaches of the first wave of scholarship in and around game cultures, Dovey and Kennedy elect to take a passionate-yet-moderate line that pragmatically negotiates a hybrid field of critical methodologies entirely appropriate to the eccentric and multifarious culture of games'. Similarly, Surman (2007 p.280) highlights that King and Krzywinska (2002) 'go beyond Ludology and its discontents, and disciplinary wrangles, to tackle some of the most pressing questions in this most recent wave of games analysis [such as] "Social, Cultural and Political” dimensions'.

It was also in 2006 that Tanya Krzywinska became the second President of the newly-formed Digital Games Research Association (DiGRA), which had been founded a few years earlier in 2003. This was a post she held until 2009, and then in 2010 two other leading British scholars, Helen Kennedy and Esther MacCallum-Stewart, became DiGRA's new President and Vice-President respectively. Between 2005 and 2010, John Salisbury, Siobhan Thomas and Diane Carr formed the London Games Research Group, and hosted a series of informal research and discussion seminars. These meetings focused primarily on core debates within the British scholarly community, such as representation, methodological practice, and diversity. Sessions provided participants with an opportunity to present and discuss their work, and several key contributions emerged from these workshops, including those by Paolo Ruffino and William Huber.

Between 2008 and 2012 the Under the Mask annual conference series was organised at the University of Bedfordshire by Allison Gazzard, Gavin Stewart and Steven Conway. The Under the Mask series was 
notable, as it was here that several national and international scholars presented their work, often for the first time, including Ashley Brown, Steven Conway, Astrid Ensslin, Jessica Enevold, Sonia Fizek, Nicolle Lamerichs, Daniel Golding, Charlotte Hagstrom and Adrienne Shaw. Over the years, this conference has showcased the vanguard of British (and international) digital game studies, with keynotes by leading scholars, including Diane Carr, Garry Crawford, Tanya Kryzwinska, Esther MacCallum-Stewart and Jason Rutter. A direct result of the Under the Mask series was the publication of Game Love: Playing with Affection (2014), edited by Jessica Enevold and Esther MacCallumStewart; a collection that joined the growing body of international research on gender, sex and sexuality in games.

In 2009 the annual DiGRA conference came to the UK for the first time, as Brunel University hosted the Breaking New Ground: Innovation in Games, Play, Practice and Theory conference. Organised by Barry Atkins, Tanya Kryzwinska and Helen Kennedy, this event included keynotes by Richard Bartle and Ian Bogost. Women in Games hosted a popular stream at the event, with a keynote by Kaye Elling, and at this conference we also saw one of the first discussions on games perseveration. This discussion, and the success of the Nottingham GameCity festival (run annually since 2006), helped contribute to the setting up of the National Video Game Arcade in Nottingham in 2015, which continues to be an important international archive and resource.

The 2010s continued to see British digital game studies punching well above its weight in terms of its contribution to international debates and the continuing development of this field and area of research. Some key books published by British digital games scholars in this decade include, but are in no way limited to, James Newman's (2004) Playing with Videogames, Helen Thornham's (2011) Ethnographies of the Videogame, Graeme Kirkpatrick's (2011) Aesthetic Theory and The Video Game, Garry Crawford's (2012) Video Gamers, Esther MacCallum-Stewart's (2014) Online Games, Social Narratives, and Seth Giddings' (2016) Gameworlds: Virtual Media and Children's Everyday Play. If Marcus 
Leaning was to repeat his content analysis of contemporary British digital games studies books, he would undoubtedly find an increased focus on the social, cultural, and political debates surrounding digital games that he noted in earlier publications. Though the topics covered by British digital games studies scholars are diverse, if there is an identity to this body of work, it is probably its contribution to expanding the parameters of research beyond a focus on defining and analysing game structures and content, to include considerations of the wider social context and culture of gaming.

In 2014 Tanya Kryzwinska brought the editorship of the journal, Games and Culture, to the UK. Also in this year, a British chapter of DiGRA was (re)launched at the University of the West of England at a daylong conference entitled Pervasive Provocations: The State of Games in the UK. This conference was followed by the formation of an advisory board for the British chapter of DiGRA led by Ashley Brown and Esther MacCallum-Stewart, which was initially named DiGRA UK; a name it retained until this changed to The British Digital Research Association (BDiGRA) in 2017.

In 2016 the inaugural class of DiGRA Distinguished Scholars included the British academics Esther MacCallum-Stewart and Tanya Kryzwinska. Also in this year, the annual DiGRA conference returned to the UK, to the University of Abertay, Scotland. This conference was organised by William Huber, Staffan Bjork and Casey O’Donnell. The conference also partnered with the Dare Protoplay festival, which showcased emerging talent in the games industry. This was the first joint event with DiGRA's sister FDG (Foundations of Digital Games) conference. In Scotland the GameThink series at the University of Glasgow, organised by Matthew Barr, ran between 2015 and 2017 and provided an 'unconference' space for discussions and the exchange of ideas (University of Glasgow 2015). Although a Scottish chapter of DiGRA had existed previously, the decision to revive the British chapter melded these groups back together. 


\section{ToDiGRA}

2017 then saw the first annual conference of the British DiGRA chapter, hosted at the University of Salford at their MediaCityUK campus, organised by Garry Crawford, Esther MacCallum-Stewart and Paolo Ruffino, and attended by over 110 delegates. This conference again included leading international names in the field, such as Chris Bateman, Aphra Kerr, Kristine Jørgensen, Jesper Juul and José P. Zagal. At the conference, a formal meeting of the British DiGRA chapter was held, nominations for the Board were collected (with online votes included), and the chapter voted to change its name to British DiGRA; in line with the naming conventions of other international chapters and national learned associations. Board members formed a social media team and a working party to examine the placement of games studies within the UK's Research Education Framework, as well as committing to plans to host an annual conference from this point onwards.

Hence, in 2018 we find British digital game studies in rude health. British scholars continue to produce a large number of very important books and papers, which are continuing to shape and push forward research into digital games, and Britain continues to host major international journals and conferences, which bring together the world's leading researchers. Also, it has to be acknowledged that British scholars and those working at British universities have, over previous decades, massively contributed to the development of digital games more generally, such as Alexander 'Sandy' Douglas' version of OXO (or 'noughts and crosses') (1952), and Roy Trubshaw and Richard Bartle's MUD (1978), to name but two early and significant contributions. Digital games would in no way be what they are today without British academics and universities. However, the history of Britain's hugely influential role in the wider development of digital games and its industry is a much larger discussion, and far beyond the scope of this short paper. What we have attempted to do here is map out just some of the key contributions British scholars have made to the international development of the study of digital games. In particular, we would suggest, if British digital game studies can be said to have contributed significantly to any one area of this developing field, it is probably most 
notably in the study of the wider social, cultural and political context of digital games; however, it must be noted that the scope and impact of British digital game studies undoubtedly goes far beyond this. It is important to note however, that this is just one (very limited) version of this history. It is how we (the authors) recall events, and how those we have asked to contribute similarly have recalled these events. This history is far from complete or comprehensive. Much of importance has been left out, due to limitations of space, or simply failing memories. We readily accept there is much more and many others of importance that we could have included. But it was not our intention to provide a definitive history, but rather to spark both memories and debates. If you recall things differently, or feel we have made major oversights or misinterpreted events, please do let us know. If British digital game studies is anything, it is a very broad church, which welcomes diverse opinions and debates; so please, join in.

\section{ACKNOWLEDGMENTS}

We would like to thank the following individuals for their memories, thoughts and contributions to this piece: Mia Consalvo, Diane Carr, Jonathan Dovey, Frans Mäyrä, Aphra Kerr, Helen Kennedy and Tanya Krzywinska.

\section{BIBLIOGRAPHY}

Aarseth, E. “Computer Games Studies, Year One”. Game Studies, 1 (1), 2001, http://www.gamestudies.org/0101/editorial.html

Atkins, B. More Than a Game: The Computer Game as Fictional Form. Manchester University Press, Manchester, 2001.

Carr, D., Buckingham D., Burn, A and Scott, G. Computer games: text, narrative and play, Polity, Cambridge, 2006.

Crawford, G. Video Gamers. Routledge, London, 2012. 
Enevold, J. and MacCallum-Stewart, E. (eds) Game Love: Playing with Affection, McFarland, Jefferson, NC, 2014.

Giddings, S. Gameworlds: Virtual Media and Children's Everyday Play, Bloomsbury, London, 2016.

Kennedy, H. and Dovey, J. Game Cultures: Computer Games as New Media, Open University Press, London, 2006.

Kirkpatrick, G. Aesthetic Theory and The Video Game, Manchester University Press, Manchester, 2011.

Krzywinska, T. \& King, G. Screenplay: cinema/videogames/interfaces Manchester University Press, Manchester, 2002.

Krzywinska, T. \& King, G. Tomb Raiders and Space Invaders: videogame forms and contexts Manchester University Press, Manchester, 2006.

Leaning, M. “The construction of video games studies in British Higher Education,” paper presented at presented at the MeCCSA annual conference, University of Bedfordshire, 11 - 13 January, 2012. http://arts.brighton.ac.uk/projects/networks/issue-16-january-2012/theconstruction-of-video-games-studies-in-british-higher-education

MacCallum-Stewart, E. Online Games, Social Narratives, Routledge, London, 2014

Newman, J. Videogames, Routledge, London, 2004.

Newman, J. Playing with Videogames, Routledge, London, 2008.

Play Research Group, The. The Play Research Group: Research. No date. http://www1.uwe.ac.uk/cahe/research/playresearchgroup.aspx

Rutter, J. \& Bryce, J. (eds). Understanding Digital Games. Sage, London, 2006. 
Surman, D. "British Game Studies? An extended review of two publications”. Animation: an interdisciplinary journal, 2 (2) 273-282, 2007.

Thornham, H. Ethnographies of the Videogame. Gender, Narrative and Praxis. Ashgate, Surrey, 2011.

University of Glasgow. Video Game Research at Glasgow, 2015, http://videogames.arts.gla.ac.uk/events/game-think/

Walkerdine, V. Children, Gender, Video Games, Palgrave Macmillan, Ba 